\title{
Experiências docentes: Subprojeto História Capes/Pibid/USP
}

Teaching experiences: History Subproject Capes/Pibid/USP

Antonia Terra de Calazans Fernandes*

Eva Aparecida dos Santos ${ }^{\star *}$

Patrícia Cerqueira Santos ${ }^{* * *}$

Renata Pellaes Corrêa ${ }^{* * *}$

\section{RESUMo}

$\mathrm{O}$ artigo trata de diferentes temas, pontos de vista e experiências de professoras envolvidas na formação de licenciandos, por meio do Subprojeto História, no âmbito do Programa Institucional de Iniciação à Docência (Capes/Pibid/USP), realizado entre os anos de 2012 e 2014, na parceria entre o Departamento de História da FFLCH/USP e Escolas Públicas da cidade de São Paulo.

Palavras-chave: formação de professores; Pibid; ensino de História.

\begin{abstract}
The text presents different themes, views and experiences of teachers involved in the training of students through the Sub Project History, from the Institutional Program of Introduction to Teaching (Capes/Pibid/USP), conducted between 2012 and 2014, in partnership between the Department of History from the FFLCH/USP and Public Schools of the city of São Paulo.

Keywords: teacher training; Pibid; history teaching.
\end{abstract}

O Programa Institucional de Iniciação à Docência (Pibid), financiado pela Capes, prioriza a formação de futuros docentes ao longo do curso de licenciatura, oferecendo bolsas de estudo aos licenciandos, supervisores (professores da rede pública) e coordenadores do projeto. No contexto do Pibid/USP,

\footnotetext{
* Departamento de História/FFLCH/USP, coordenadora do Subprojeto História Capes/Pibid/ USP. antoniacalazans@gmail.com

** Professora da Rede Pública de São Paulo, Supervisora do Subprojeto História Capes/Pibid/USP. eva.santos@yahoo.com.br

*** Professora da Rede Pública de São Paulo, Supervisora do Subprojeto História Capes/Pibid/ USP. patriciacerquer@gmail.com

**** Professora da Rede Pública de São Paulo, Supervisora do Subprojeto História Capes/Pibid/ USP.rpellaes@hotmail.com
} 
foram organizadas diferentes propostas submetidas à aprovação da Capes. Em 2012 foi aprovado o Subprojeto História para desenvolver a temática da História Indígena na escola, e em 2014 foi aprovado o Subprojeto com o tema da Diversidade.

Em 2012, o subprojeto contou com duas professoras supervisoras e dez licenciandos. E, a partir de 2014, o grupo de História foi subdividido entre quatro coordenadores. Nesse novo contexto, como uma das coordenadoras, ficaram sob minha responsabilidade três supervisores e 16 estudantes.

A experiência que aqui está sendo relatada condensa vivências e reflexões englobando as atividades desde 2012, sob a perspectiva da coordenação e de três professoras supervisoras. ${ }^{1}$

Inicialmente, é importante explicitar os procedimentos no desenvolvimento do projeto. Primeiro, foram abertos editais para selecionar professores e licenciandos. Depois, sugeriu-se aos supervisores escolhidos que apresentassem aos diretores e coordenadores das escolas os objetivos do programa e do subprojeto, debatendo a possibilidade de receberem as atividades e os alunos da USP na escola. Na sequência, realizou-se a visita da coordenação às instituições e uma carta de aceite foi redigida e assinada pela direção.

Em 2012, as primeiras atividades envolveram estudos a respeito da profissão docente (Tardiff, 2001). Na sequência, estudos teóricos e históricos atendendo à Lei no 11.645/08, que estabeleceu a obrigatoriedade da História dos Povos Indígenas na escola. A primeira iniciativa foi orientada para subsidiar a construção de diagnósticos do que os alunos na escola sabiam e pensavam a respeito do tema. Por conta disso, solicitou-se uma pesquisa para escolha de autores que favorecem embasamento para estudo de representações (Chartier, 2002), e, na sequência, o estudo específico de textos que tratavam mais diretamente da história dos povos indígenas no Brasil (Almeida, 2010). Para o desenvolvimento dessas atividades, foram organizadas reuniões coletivas na universidade.

O subprojeto perseguiu, em seus trabalhos, a possibilidade de oferecer aos licenciandos vivências de diferentes etapas do processo de planejamento de situações de ensino e aprendizagem. Nesse sentido, incluiu entre as atividades do professor diagnosticar o que os alunos sabem sobre determinado tema de estudo histórico. Com essa preocupação, foi proposto aos licenciandos criarem 
instrumentos para identificarem o que os alunos do ensino fundamental e médio sabiam e pensavam a respeito dos povos indígenas.

Em 2012, foram organizados materiais que os alunos aplicaram em todas as salas de aulas das escolas, e também entre os professores. Os resultados foram sistematizados e avaliados, resultando em diretrizes para escolha de temas de oficinas. Na sequência, individualmente e em grupos, os licenciandos estruturaram propostas, materiais didáticos e, junto aos supervisores, no ano de 2013, ofereceram nas escolas oficinas de diferentes formatos.

Em 2014, o subprojeto foi reorganizado para dar conta de questões identificadas pelos licenciandos entre os adolescentes, ampliando, assim, o tema para Diversidade, considerando mais amplamente etnia e gênero. Com um grupo parcialmente novo e escolas novas, iniciou-se o processo de aproximação entre universidade e escola, os estudos teóricos foram retomados, ampliados os temas históricos para aprofundamento, estruturados novos diagnósticos (com novas temáticas) e, em 2015, estão sendo sistematizados e debatidos para subsidiar a produção de materiais e estratégias de ensino para as oficinas a serem oferecidas no ambiente escolar.

Nesse novo contexto, foram retomados os textos de valorização dos sabres dos professores e estudos mais aprofundados da história afro-brasileira (Alberti, 2013; Dias, 1985) e da questão de gênero (Dias, 1994; Spargo, 2006). Realizou-se uma visita de campo ao Quilombo Cafundó (Salto de Pirapora, Sorocaba, SP); organizou-se uma oficina com a temática da música afro-brasileira - jongo, e todos participaram da oficina do prof. dr. Carlos José Ferreira dos Santos, com lideranças Tupinambá da região de Olivença, na Bahia, sobre a história indígena no Brasil e as lutas empreendidas por esses povos pelo direito às terras e a vida nas aldeias. Como nos anos anteriores, os alunos também visitaram as escolas para serem apresentados ao diretor e aos professores, e retornaram para participar de reuniões pedagógicas e desenvolver atividades nas salas de aula.

Um projeto que tem sido desenvolvido há cerca de 3 anos tem muitas experiências a serem compartilhadas, e esse é o propósito deste texto que apresenta olhares e interpretações de uma equipe de professoras politicamente engajadas com a valorização da escola pública e do necessário diálogo e parceria entre a escola e a universidade. Cada uma escolheu uma perspectiva 
específica para escrever sobre o programa, considerando do ponto de vista da escola, da formação do licenciando e dos saberes dos alunos.

Atualmente, uma nova política do Pibid tem orientado a valorização também do trabalho e estudos dos professores supervisores, partindo do princípio de que todos que estão envolvidos no programa estão em processo de formação profissional. Os textos que se seguem, dentro desse contexto, estão identificados, portanto, por suas autoras, particularizando interesses temáticos daquelas que fazem a mediação entre a universidade e a escola na situação de formação de futuros docentes.

\section{Os efeitos do Pibid na escola}

por Renata Pellaes Corrêa

A presença de estagiários na escola, de modo geral, suscita sentimentos diversos. Parte dos professores tem em mente a impressão de que esses jovens estudantes universitários são elementos estranhos à sua aula, que ficam sentados num canto quase oculto da sala para observar e julgar. Pior ainda, os licenciandos podem também ser entendidos como elementos de distração para os alunos, uma vez que a novidade sempre atrai olhares. Muitos pensam que eles não têm interesse na prática escolar, que comparecem apenas para cumprir uma exigência de seu curso de licenciatura. Outros ainda consideram o estagiário como uma espécie de ajudante, alguém que pode dar suporte nos aspectos mais pragmáticos da aula.

Tais preconceitos quanto à presença dos jovens universitários na escola, infelizmente, não estão totalmente descolados da realidade. De fato, a forma como os estágios são organizados pelas instituições de ensino superior contribui para esse imaginário. Na maioria dos casos se resumem a relatórios a serem entregues baseados em determinado número de horas de observação a serem cumpridas na escola. A proposta do Programa Institucional de Bolsas de Iniciação à Docência (Pibid) rompe com esse padrão. Ao participar da seleção para o programa, ao receber uma bolsa para o desenvolvimento das atividades, os estudantes assumem um compromisso com o estágio, que não é visto apenas como uma etapa a cumprir, mas como parte de sua formação profissional. 
Por sua vez, a figura do Professor Supervisor estabelece um vínculo entre a Escola e os bolsistas do Programa. Ao integrar um projeto que é também da escola, os bolsistas não ficam isolados como elementos estranhos à sua realidade. Para o Professor Supervisor o desenvolvimento das atividades com os estagiários do Pibid é também uma possibilidade de renovação, um processo de formação na prática. $\mathrm{O}$ desenvolvimento do projeto coloca novamente o profissional em contato com o mundo acadêmico. Participar das reuniões, leituras e debates promovidos no grupo do Pibid é uma maneira de contribuir com o aprendizado dos futuros docentes sobre a profissão, mas é sobretudo uma oportunidade de refletir sobre a própria prática, de conhecer novos autores e suas teorias. Assim tem ocorrido na minha experiência como professora supervisora no subgrupo do Pibid História USP, coordenado pela professora Antonia Terra.

Nesse subgrupo, a premissa fundamental para o desenvolvimento das atividades é a de que o trabalho desenvolvido é realizado de maneira coletiva, em nossas reuniões e debates todos contribuem de maneira democrática. Deste modo, mesmo que haja uma hierarquia organizacional, todos os membros têm o mesmo direito a opinar e também devem assumir a mesma responsabilidade no planejamento e organização das ações. Esse é um grande diferencial do Projeto, pois todos os envolvidos são autores de sua prática.

As reuniões de estudo, planejamento e análise são marcadas por debates acalorados, pelo entusiasmo dos bolsistas. O papel dos professores supervisores é contribuir com sua experiência profissional, oferecer um olhar de quem está inserido na realidade escolar. Nesse processo, a presença de três professores que vivem realidades distintas e têm personalidades diferentes é muito interessante, pois um complementa a contribuição do outro.

Além disso, é preciso estudar muito para fundamentar nossas intervenções não apenas na experiência, mas também na teoria. Os bolsistas do Pibid são alunos atentos e questionadores, além disso, nossa temática de estudo, que inclui sob o guarda-chuva das diversidades questões relativas à história indígena, dos descendentes de africanos e das mulheres, demanda estudo, pois embora sejam temas cruciais para a compreensão da contemporaneidade, não são tradicionalmente estudados nos cursos de formação de professores. Nesse 
sentido, somos levados a reconhecer que ser professor é um processo constante de aprendizagem, é uma construção, não um estado.

Essas são características bastante enriquecedoras do projeto, pois somos levados não apenas a constantemente relacionar teoria e prática, mas também a refletir e muitas vezes questionar nossas atitudes e posicionamentos.

Tanto em nossos encontros, quanto nas intervenções planejadas para acontecer na escola, buscamos fugir a um modelo expositivo, valorizando um formato de debate no qual todos têm voz e cuja participação ativa é estimulada.

Como exemplo desse processo, gostaria de destacar um debate que ocorreu no segundo semestre de 2014 em torno da seleção de materiais para uma atividade a ser desenvolvida nas escolas. Depois de muitas reuniões para definir o formato que as atividades deveriam ter e os materiais que deveriam ser utilizados, os bolsistas, com o apoio dos supervisores, selecionaram um conjunto de imagens que dariam corpo à intervenção. Nessa seleção, uma das imagens me desagradou, mas num primeiro momento eu não sabia dizer o motivo, e por isso decidi não me pronunciar. Depois de voltar para a escola, observar meus alunos, imaginar como seria realizada a atividade, é que pude ver mais claramente os motivos que me levaram a questionar a validade daquela imagem específica como parte de nosso material didático. Depois de uma conversa com outros supervisores e com a coordenadora do subgrupo decidimos excluir aquela imagem da intervenção. Obviamente esse processo demandou explicações aos bolsistas, afinal de contas era seu trabalho e esforço que estava em jogo. Na conversa com os bolsistas, esclarecemos os problemas que potencialmente viriam com a utilização da imagem, especialmente levando em conta os limites de nossa atuação e as características de nosso público-alvo, alunos do ensino fundamental. Depois de muitas conversas, creio que todos concordaram com a decisão da exclusão da imagem. Esse episódio foi importante para percebermos algumas coisas óbvias que às vezes esquecemos: que ao preparar qualquer atividade é imperioso levarmos em conta o público-alvo de nossas ações; que é necessário tentar visualizar de que maneira nossas intenções podem ser concretizadas ou não dentro das condições concretas que nos são oferecidas; que é preciso também nos questionarmos sobre a relevância de nossas intenções para o objetivo que queremos alcançar. Talvez esse seja o 
papel do Professor Supervisor, trazer um olhar mais maduro para a ação dos bolsistas, mas numa relação que não reprima a criatividade deles.

Por sua vez, as interferências do Pibid na escola, que acontecem na forma de oficinas idealizadas pelo grupo de bolsistas em conjunto com os supervisores e a coordenação, acabam por mobilizar a organização das atividades escolares de modo diferente do habitual. Esse é um recurso que potencialmente ajuda na crítica a um modelo de escola mais fechado ou estático. A presença do "outro" num ambiente conhecido nos oferece recursos para olhar nossa prática desde um novo patamar. A mesma metodologia que escolhemos para nossos encontros é a que pretendemos levar para a escola, e isso não se restringe apenas às intervenções dos bolsistas, mas se reflete em nossa prática cotidiana.

Outro ponto de partida para as atividades relacionadas a esse grupo é a valorização da Escola como uma instituição produtora de saberes. É por isso que, além dos temas específicos de história, também se reserva um tempo para o estudo de teorias relativas à própria cultura escolar. Esse é um aspecto relevante pois, quando os estagiários do Pibid chegam à escola, estão amparados por um arcabouço teórico que favorece a percepção desse espaço como palco de ação e criação, onde está favorecido um enlace entre teoria e prática.

É o respeito pela Escola como instituição, e pelas diversas unidades escolares em suas especificidades, que torna tão notáveis as contribuições do Pibid. O primeiro contato com as escolas se faz por intermédio do próprio Professor Supervisor que, como membro da comunidade escolar, decide participar do projeto, mas a primeira atividade oficial do Pibid na escola se dá num encontro da Coordenação do grupo com a equipe gestora da escola. Esse encontro inicial é importante para preparar o território de ação dos estagiários, ele marca o respeito do grupo pela instituição e também sela as propostas do Pibid em cada Unidade Escolar.

Posteriormente, os alunos visitam as escolas para conhecê-las e observá-las. Nessa jornada, são acompanhados pelo Professor Supervisor. A presença desses jovens universitários andando pelos corredores e salas da escola agita o ambiente. Tanto os alunos quanto os adultos querem interagir, saber quem são aquelas pessoas. Apenas a presença do grupo na escola já significa uma quebra de rotina, o que por si já pode significar um convite para a reflexão. 
Mesmo nas questões mais cotidianas, as soluções dos alunos podem ser surpreendentes e renovadoras. Lembro que num momento em sala de aula, durante a aplicação de uma atividade diagnóstica, ligada ao tema da História das Mulheres, um aluno fez um comentário de fundo machista que incomodou uma colega. A solução dada por uma das estagiárias foi muito espontânea e eficiente. Ela chamou a atenção do aluno alegando que aquela não era uma brincadeira adequada, pois só o seria quando todos os envolvidos se divertissem, não quando alguém saísse com os sentimentos feridos. Além disso, a estagiária acrescentou que ela não poderia aceitar nenhum tipo de violência contra uma menina, que o machismo é uma agressão contra todas as mulheres. A intervenção da bolsista ocorreu de maneira natural, sem tom de "bronca". Talvez essa leveza tenha feito os alunos, e não apenas aqueles envolvidos na discussão, ouvir com mais atenção e sem muita resistência.

Em outra turma eu estava muito preocupada, sem saber como se daria a inclusão de uma aluna portadora de necessidades especiais, com grande dificuldade de concentrar-se e de se expressar. O que parecia ser um grande problema para mim, não foi para os bolsistas. De forma muito natural, um dos bolsistas se aproximou da aluna, ganhou sua atenção e conseguiu que ela participasse da atividade a seu modo. Esse foi um momento de grande alegria pessoal e é um exemplo da importância da atuação dos bolsistas, pois ela também ajuda a enxergar melhor a individualidade de nossos alunos.

A leveza da atuação dos bolsistas se contrapõe à rigidez que muitas vezes nos é imposta pela rotina escolar, e acaba propiciando exemplos práticos de como melhorar essa mesma rotina. Atitudes e valores são partes importantes do saber escolar. As intervenções dos bolsistas na escola constituem, assim, oportunidades de aprendizado interessantíssimas, também para nós supervisores. Oportunidades que nos levam a enxergar e questionar nossos próprios conceitos e preconceitos, momentos que nos dão força para lutar pela construção de uma escola mais leve. O que se estabelece, em minha opinião, é uma relação dialética, na qual o saber escolar e o saber acadêmico são constantemente recriados. 


\section{FORMAÇÃO DO LICENCIANDO}

por Patrícia Cerqueira Santos

Sentir na pele o desafio que é a Educação, por um lado, nos faz valorizar mais os profissionais que lutam diariamente para construir um espaço de construção de conhecimento e não só de reprodução ou vulgarização.

Bolsista Pibid

A epígrafe permite iniciar um diálogo sobre o que foi a experiência de participação de alunos da licenciatura do curso de História da Universidade de São Paulo (USP) no Programa Institucional de Bolsa de Iniciação à Docente (Pibid) com a temática indígena. De agosto de 2012 a dezembro de 2013, numa pareceria entre a USP e duas escolas públicas estaduais, uma na Zona Leste e outra no extremo sul da Zona Sul da Cidade de São Paulo, os estudantes puderam vivenciar novas práticas na sua formação como futuro professor.

Para analisar essa experiência foram utilizadas, como parte dos documentos, as cartas de intenção escritas pelos bolsistas ao entrarem para o programa. Nessas cartas, de modo geral, estão imbricados desejos por um conhecimento mais profundo da história dos povos indígenas no Brasil, por maior conhecimento a respeito das sociedades nativas da América e interesse pelo ensino. Explicitam que o interesse de envolvimento com o programa é de se tornarem professores que consigam ótimos resultados dos alunos em sala de aula.

Além das cartas de intenção, foram organizadas entrevistas com bolsistas do programa. Sugeriu-se a eles um guia de temas com base na seguinte proposta:

Se você sugerir para um aluno da licenciatura a entrada ou não no Pibid, o que você escreveria sobre o projeto, sua formação, a relação do bolsista com a escola, os colegas, a professora supervisora, a produção de material e a construção das oficinas de intervenção na escola, a ida à escola?

Dos oito licenciandos consultados que participaram do programa naquele período, quatro deram retornos, todos do sexo masculino. Três deles estão atuando como professores, dois dos quais em escola pública e um em escola 
particular. Atribuímos, então, o número 1, 2, 3 para os bolsistas que, nos anos seguintes, tornaram-se professores, e o número 4 foi para o bolsista que continua como estudante da universidade e atuando no Pibid.

$\mathrm{Na}$ análise dos retornos dos estudantes, transparecem algumas questões importantes para serem pontuadas. Uma delas diz respeito a uma narrativa comum que revela a importância de passar pela experiência proporcionada pelo programa na formação inicial, pautada na relação entre universidade e a escola. O bolsista 1 escreveu: "muitas vezes chega-se à escola com nenhuma experiência. O risco de se idealizar o espaço pode levar a muitos a frustração...”. Por meio da inserção no programa, esse risco pode ser atenuado quando ao licenciando é oferecida a oportunidade de contato direto com as práticas e saberes escolares, por meio da "prática de refletir sobre as práticas, de trabalhar sobre as práticas, de saber como fazer” (Nóvoa, 2006).

Cabe destacar, com base nos retornos dos licenciandos, o fato de que o reconhecimento do professor na escola, como produtor de saberes, já revela um olhar humanizado para esse profissional que atua em situações adversas. E evidencia a importância do trabalho conjunto e próximo dos futuros docentes com os professores que os recebem e orientam na escola, assim como com os fundamentos teóricos dos estudos bibliográficos escolhidos para serem aprofundados e debatidos na universidade (Tardiff, 2001).

A presença no cotidiano da escola, conhecendo melhor sua organização mais estrutural, foi tema também considerado importante pelos estudantes. Um deles destacou: "o projeto permite um contato com a escola e assim um conhecimento que nem sempre é acessado através de textos sobre a estrutura escolar" (Bolsista 4). E outro ressaltou:

as dificuldades das escolas públicas quanto a seus espaços, equipamentos, as temporalidades do cotidiano escolar e os desafios de pôr um projeto temático no universo escolar constituíram um aprendizado indispensável para o futuro professor. (Bolsista 2)

O contato do bolsista com a escola, mediado pela professora supervisora e planejado previamente em pareceria com a universidade, foi fundamental na elaboração dos projetos conjuntos de visita e de oferecimento de oficinas.

Em decorrência dos procedimentos de formação ao longo do trabalho do subprojeto História, uma questão que aparece nos textos dos bolsistas é a 
valorização da propositura de uma prática de formação docente pautada na metodologia do trabalho coletivo. O reunir-se para estudar, planejar, trocar ideias, compartilhar dúvidas, receios, perspectivas e experimentar fazer, consolidou-se como uma boa referência. Um bolsista escreveu: "lembro com carinho das manhãs que passávamos discutindo, conversando sobre como montar a aula" (Bolsista 3). "Pensar a educação partindo da dúvida e do questionamento não é fácil. Exige muito conhecimento teórico (sobre o tema a ser ensinado e sobre as questões pedagógicas)" (Bolsista 1). "O projeto é uma construção coletiva que possui como horizonte a troca de informações" (Bolsista 4).

Os procedimentos metodológicos de estudo, pesquisa e atividades práticas, importante compromisso do subprojeto, consolidaram-se nas referências descritas nos textos dos licenciandos. Um deles escreveu:

As oficinas são preparadas a partir de todo um processo no qual se parte dos conhecimentos dos próprios estudantes. Para isso, é realizado um conjunto de atividades prévias a fim de compreender seu raciocínio e como ele entende um determinado tema. (Bolsista 4)

O bolsista, nesse caso, faz referência aos diagnósticos, quando elaboraram material para conhecerem o que os alunos das escolas sabiam e pensavam sobre a "história indígena". Da perspectiva do docente na escola, orientando futuros professores, a valorização dessa atividade na memória do licenciando expressa a conquista de instigá-los a entender os alunos como agentes ativos, que pensam e refletem a respeito de diferentes temas sociais e históricos, e não como lousa vazia que deve ser preenchida com conteúdo dissertado pelo docente. Foi com base no princípio de respeito aos alunos e professores da escola que os bolsistas construíram as oficinas desenvolvidas.

Como professora da rede pública de São Paulo, vejo como promissora a formação para atuação na escola a partir do trabalho coletivo, considerando que em muitas ocasiões os professores sentem-se solitários na realização de seu trabalho, apesar das reuniões pedagógicas semanais. Talvez esses bolsistas, com base nesse olhar humanizado, possam compartilhar com outros docentes a experiência vivida no Pibid e provocar o debate e, esperançosamente, mudanças. 
A possibilidade de receber dos estudantes suas avaliações a respeito do programa de formação de docentes foi muito gratificante, não só por avaliar como aprenderam ao longo dos processos nos quais estiveram envolvidos, como também por conta de expressarem seus compromissos e memórias com a escola pública. Nessa perspectiva, um bolsista escreveu:

As atividades de pesquisa, produção de materiais, planejamento e aplicação das oficinas com alunas e alunos foi de fundamental importância para a minha formação como professor, além de me aproximar do ambiente saudoso, diverso culturalmente e cheio de boas surpresas no qual passei grande parte de toda a minha infância e juventude, que é a escola pública. (Bolsista 3)

Por conta da minha participação, como mediadora na formação desses estudantes universitários, ficaram muitas aprendizagens sobre os saberes que temos e as práticas inovadoras que podemos construir e desenvolver na escola. Alguns deles já se tornaram professores e outros permanecem nas universidades, com planos para a entrada nos programas de pós-graduação, sem excluir a possibilidade de ingressarem no futuro no magistério, mesmo pós-graduados. O que é comum a todos eles e ficou expresso nos textos que produziram e me enviaram foi a defesa da profissão docente e da escola pública.

\section{Os ALUNOS, A MULHER, O TRABALHO E O INDÍGENA}

por Eva Aparecida dos Santos

Desde o segundo semestre de 2012, sou supervisora do Subprojeto História, inserido no Projeto Capes/Pibid/USP, vinculado ao departamento de História/FFLCH/USP, sob a coordenação da professora Antonia Terra. Em 2012 e 2013, o subprojeto focou a temática da Lei 11.645/08, especificamente com a História Indígena no ensino. $\mathrm{Na}$ época, eu lecionava em uma escola estadual que oferecia ensino fundamental II e médio. E, como atividade do subprojeto, participei de intervenções pedagógicas na escola.

Uma das primeiras atividades consistiu em realizar um diagnóstico para identificar conhecimentos prévios de alunos e professores a respeito da história dos povos indígenas brasileiros. Para organizar o diagnóstico, realizaram-se algumas reuniões com os licenciandos para decidir como deveria ser feito. A 
opção foi utilizar imagens com a temática indígena. E, para isso, o grupo escolheu um conjunto de desenhos encontrado no livro Aprendendo português nas escolas da floresta (Brasil, 1997, p.11). As imagens escolhidas retratam cenas do cotidiano de povos indígenas do Acre: mulher e criança, uma partida de futebol, crianças indo à escola, pessoas indo pescar, mulher fazendo artesanato.

Para o desenvolvimento da atividade na escola, a escolha foi não informar aos estudantes sobre o tema das imagens. Elas deveriam ser apresentadas nas salas de aula e, a partir delas, os alunos deveriam escrever um texto. Nosso objetivo era interferir o mínimo possível nas decisões dos alunos.

A atividade foi realizada com todos os alunos da escola, um total de 42 turmas, com uma média de 30 alunos por sala, divididos em três turnos. Duas folhas foram entregues a cada estudante: uma delas consistia em uma reprodução das imagens extraídas do livro didático, e a outra era onde deveriam realizar a atividade. Solicitamos que escrevessem nessa segunda folha o nome, a idade e a série de cada um, e escrevessem uma história com título a partir das iconografias apresentadas. Tendo em vista que muitos alunos gostavam de desenhar e alguns não gostavam de escrever, podiam escrever e desenhar para complementar suas histórias, ou apenas desenhar. Desejávamos que os estudantes se sentissem livres para participar ou não da atividade. Menos de dez alunos do total decidiram não participar.

Realizada a atividade, ficamos diante de centenas de histórias sobre os mais diversos temas. Para facilitar o trabalho de análise, decidimos criar uma série de categorias. A primeira consistia em separar os textos produzidos que explicitavam a temática indígena daqueles que "não identificavam ou não optavam" por abordar a temática. Esse primeiro filtro se justifica considerando que apesar de não termos citado a questão indígena antes e durante a aplicação das atividades, algumas cenas retratadas traziam elementos comumente associados a esses povos. Identificadas essas referências por alguns alunos, eles passaram a compartilhar suas impressões com a classe, de modo que todos os alunos sabiam que havia alguma relação entre as imagens e a questão indígena ("é sobre índio", "tem índio nesse retrato", "é para falar de índio" etc.). Assim sendo, o fato de muitos jovens não terem explorado o tema nos textos que produziram não se deve à não identificação, mas a outros motivos, que podem estar relacionados ao 
desconhecimento e/ou conhecimento insuficiente para elaborar uma história e discutir temas com os quais não estavam familiarizados.

A análise das atividades indicou que apenas 39\% dos alunos inseriram “indígenas" em suas narrativas. Em grande parte, suas ideias gerais acerca do tema se assemelham ao senso comum difundido na nossa sociedade sobre esses povos, ou seja: índios congelados no tempo; que vivem apenas em florestas distantes; protetores da natureza; que vivem em extrema pobreza, e que estão fadados ao desaparecimento e à perda de sua identidade cultural.

Quanto aos professores da escola, todos foram informados sobre a proposta do projeto. Fizeram a mesma atividade, e todos escreveram sobre os indígenas. Em seus textos houve um esforço para escrever "certo", construir um discurso politicamente correto. Porém, expressaram desconhecimento do tema e ideias de senso comum também encontradas nos textos produzidos pelos alunos.

De modo amplo, quanto às interpretações dos alunos em relação às imagens entregues, foi possível identificar alguns valores semelhantes aos frequentemente correntes na sociedade brasileira em geral. As figuras femininas nas imagens foram interpretadas como "mães" e, assim sendo, a mulher se tornou a grande personagem da maioria das histórias. Em mais de $60 \%$ das narrativas, os estudantes relacionaram as figuras com mulheres trabalhadoras que se revezavam entre os afazeres domésticos e trabalhos remunerados, para sustentar a família. Os trabalhos manuais - costura, crochê/tricô, cerâmica -, muitas vezes associados às mulheres trabalhadoras, se destacaram como a fonte de renda mais escolhida pelos alunos.

A análise mais específica dos textos produzidos pelos jovens do $3^{\circ}$ ano do ensino médio pode ser exemplo dos resultados dos diagnósticos realizados. Entre esses alunos, ao contrário das demais classes da escola, os textos expressaram explicitamente relações com os povos indígenas, $56 \%$ do total. E, de acordo com a maioria dos alunos, as principais características atribuídas aos povos indígenas foram: cultura diferente dos não índios; costumes típicos; transmissão dos costumes para os filhos e crianças da comunidade; comunidade adotando um novo costume; comunidade autossustentável; comunidade onde há divisão sexual do trabalho; comunidade que preserva a natureza; comunidade isolada em florestas/mato/lugares muito distantes; nudez associada aos costumes; índios vivendo em casas típicas. Em relação às condições de vida, 
a maior parte dos alunos retratou precariedade, falta de recursos, porém harmonia familiar, felicidade em vida simples. Para os alunos, parte dos problemas enfrentados pelos indígenas na atualidade é resultado de ações empreendidas pelos "brancos" que degradaram, poluíram seus locais de moradia e trouxeram doenças e modificação no seu modo de vida. Estranhamente aliada a isso, muitos alunos defenderam a ideia de que ir viver nas cidades e adotar um modo de vida capitalista pode ser uma forma para que essas populações possam melhorar as condições materiais de suas comunidades e levar a elas o desenvolvimento.

As mulheres indígenas são descritas como mães zelosas, trabalhadoras, responsáveis pelos cuidados com a casa e com a fabricação dos artesanatos. Em algumas narrativas houve referências ao não reconhecimento do trabalho da mulher, descrito como mais "duro" que o realizado pelos homens (de sete, apenas dois foram elaborados por alunos do sexo masculino). A escolarização dos indígenas é considerada com naturalidade e importante para o desenvolvimento cultural e material dos povos, porém a presença da escola nas comunidades se deve à bondade do homem branco, do europeu, dos políticos que levam desenvolvimento para essas comunidades. O desenvolvimento pode chegar às aldeias também pela ida de indígenas para as cidades, onde após ganharem dinheiro (por meio do futebol ou do estudo) voltam para levar "progresso" à comunidade. As mulheres, também, desempenham um papel importante nesse setor: em muitas das histórias, após realizar as tarefas do dia, andam quilômetros durante a noite a fim de se escolarizar e ensinar o que aprenderam para os outros membros das comunidades. Quanto à tecnologia, poucos alunos associaram seu acesso à perda dos costumes e de um modo de vida imaginado como "tradicional".

Preconceitos e formas inapropriadas foram utilizados em algumas narrativas para fazer referência aos moradores das aldeias. Porém, acredito que não havia necessariamente um sentimento negativo em relação a esses povos, mas acesso a informações errôneas sobre eles, e dificuldades de encontrar os conceitos adequados para tratar temas específicos: "hoje podemos dizer que eles já se adaptaram aos costumes e vivem como pessoas normais", "quando os humanos chegaram na tribo", "antigamente quando Kairu era pequena ela vivia em situação precária. As crianças não iam à escola e andavam despidas e sujas na aldeia”. 
Os estudantes que não identificaram ou não optaram por abordar a temática indígena, narraram em seus textos: a trajetória de mães que lutam para educar os filhos e dar melhores condições de vida à família; a ascensão social por meio do futebol; problemas relacionados à pobreza, escassez e precariedade das condições materiais; e a realização e a felicidade familiares. Alguns alunos utilizaram o texto para narrar suas histórias de vida, fazer projeções para o futuro, criticar o governo e criticar a escola. Neste último caso, fizeram críticas indiretas: "Lá eles tinham um bom aprendizado, apesar de ser um lugar onde não havia gente qualificada para exercer a função de professor"; "escola onde não há mestres, só professores que enrolam até tocar o sinal”. A escola, seguida do futebol, é entendida como meio para melhorar as condições de vida.

Algumas narrativas evidenciaram preocupantes preconceitos contra os indígenas, negros e, sobretudo, mulheres, expressos nos textos e nos diálogos em sala de aula ao longo da realização da atividade.

Muitas histórias discorriam sobre mulheres que ao engravidar foram abandonadas por seus companheiros, porém quando eram índios ou negros, era essa característica que determinava sua conduta: "mas depois de um tempo, o 'tal índio' sumiu e a deixou grávida de 3 meses"; "Malu aos 20 anos engravidou de um índio que não era nada na aldeia, e logo ficou sabendo que ele fugiu da tribo para não assumir o filho"; "alguns dias depois a menina branca descobre que está grávida e resolve ir falar com ele, e o negro fala que o filho não é dele e diz que não vai cuidar da criança ... se lamentando pelo que aconteceu, e assim ela foi criando seu filho negro sozinha por muitos e muitos anos".

Algumas atividades foram entregues com narrativas que traziam um discurso de respeito às diferenças e às escolhas de cada um, porém complementadas com versos e escritos incitando o ódio a "macacos", fazendo referência ao suposto mau cheiro de bolivianos (na época, a escola tinha um número considerável de alunos de origem andina).

No que concerne às mulheres, apesar das descrições elogiosas reservadas às mães indígenas e não indígenas, um número considerável expressa machismo, violência, ofensas: "Pois como nem todas mulheres conseguem concluir os estudos, geralmente, por conta da gravidez. São essas mulheres derrotadas que viram dependentes de seus maridos, que o usam como empregado (quadro 3), e assim depois de nascer seu filho, passa o resto da vida em pró dele (quadro 2)" (A história de uma mulher, $\mathrm{G}^{\star * * *} 1,17$ anos). 
Um exemplo contundente da complexidade dos valores expressos pelos estudantes é este texto:

No primeiro quadro, pode-se observar que a mulher da imagem é do tipo 'Amélia, esse tipo de fêmea. Podemos resumir suas atitudes em cuidar da casa, cuidar do marido, nunca cobiçar nada por interesse financeiro. No segundo quadro a mulher deixou de ser 'Amélia', optou por um relacionamento de poligamia, devido a isso se relaciona com os seis homens jogando futebol no quadro seis, e até hoje não sabe quem é o pai do seu filho. Consequentemente no quadro três ela está sozinha, infeliz, lavando roupas no rio, pois sua casa não tem água encanada, sem dinheiro seu filho no quadro cinco caminha dez $\mathrm{km}$ todos os dias descalço para ir a escola e voltar. Enquanto isso no quadro quatro os seis homens que tiveram o relacionamento poligâmico com essa triste moça estão passeando em uma cachoeira com suas esposas num relacionamento monogâmico com muito amor e orgulho. Mulheres que esquecem seu valor e se relacionam com vários homens é abandonada. Na lógica do macho alfa, se foi abandonada é resto e se é resto não iremos nos satisfazer com isso. Logo essas rejeitadas e mães solteiras irão de devem morrer sozinhas, pois já perderam seu valor como candidatas à esposa. (sem título, $\mathrm{A}^{* * 1,18 \text { anos) }}$

Os textos e desenhos produzidos pelos alunos constituíram material diagnóstico que subsidiou a elaboração de oficinas oferecidas em duas escolas, para alunos de diferentes idades, contemplando a história de povos indígenas no Brasil por meio de estudos de cultura material, sonoridades e musicalidade indígena e debates sobre a questão da terra, entre outros temas. Durante a elaboração das atividades de intervenção procuramos introduzir conteúdos que levassem os alunos a refletir sobre a diversidade, em razão das questões preocupantes que observamos nas narrativas produzidas por eles.

\section{REFERÊNCIAS}

ALBERTI, Verena. Algumas estratégias para o ensino de história e cultura afro-brasileira. In: PEREIRA, Amilcar; MONTEIRO, Ana Maria (Org.) Ensino de história e culturas afro-brasileiras e indígenas. Rio de Janeiro: Pallas, 2013. p.27-55.

ALMEIDA, Maria Regina Celestino de. Os índios na história do Brasil. Rio de Janeiro: Ed. FGV, 2010. 
BRASIL. Ministério da Educação. Comissão Pró-Índio. Aprendendo português nas escolas da floresta. Brasília: MEC; Unesco; CPI-AC, 1997.

CHARTIER, Roger. A história cultural: entre práticas e representações. Lisboa: Difel, 2002.

DIAS, Maria Odila da Silva. Nas fimbrias da escravidão urbana: negras de tabuleiro e de ganho. Estudos Econômicos, v.15, nº especial, p.89-109, 1985.

. Novas subjetividades na pesquisa histórica feminista: uma hermenêutica das diferenças. Estudos Feministas, v.2, n.2, p.373-382, 1994.

NÓVOA. António. Desafios do trabalho do professor no mundo contemporâneo. Palestra proferida no Sindicato dos Professores de São Paulo (Sinpro-SP), out. 2006. Disponível em: www.sinpro.org.br/noticias.asp?id_noticia=639; Acesso em: 1 mar. 2015.

SPARGO, Tamsin. Foucault e a Teoria Queer. Rio de Janeiro: Pazulin; Juiz de Fora: Ed. UFJF, 2006. p.18-25 e 87-89.

TARDIFF, Maurice. Os professores enquanto sujeitos do conhecimento: subjetividade, prática, e saberes no magistério. In: CANDAU, Vera Maria (Org.) Didática, currículo e sabres escolares. Rio de Janeiro: DP\&A, 2001.

\section{NOTA}

${ }^{1}$ A professora Eva Aparecida dos Santos permanece no subprojeto desde o início; Patrícia Cerqueira Santos participou nos anos de 2012 e 2013, e Renata Pellaes Corrêa ingressou em 2014.

Artigo recebido em 22 de abril de 2015. Aprovado em 6 de julho de 2015. 